\title{
Antimicrobial residues in tissues and eggs of laying hens at Chittagong, Bangladesh
}

\author{
Ariful Islam¹,2,3, A. K. M. Saifuddin ${ }^{3}$, Abdullah Al Faruq ${ }^{4}$, Saiful Islam ${ }^{5}$, Shahanaj Shano ${ }^{6}$, Mahabub Alam and \\ Mohammad Mahmudul Hassan ${ }^{3}$
}

1. EcoHealth Alliance, New York, NY, USA; 2. Institute of Epidemiology, Disease Control and Research, Mohakhali 1212 , Bangladesh; 3. Department of Physiology, Biochemistry and Pharmacology, Faculty of Veterinary Medicine, Chittagong Veterinary and Animal Sciences University, Chittagong 4225, Bangladesh; 4. Department of Anatomy and Histology, Faculty of Veterinary Medicine, Chittagong Veterinary and Animal Sciences University, Chittagong 4225, Bangladesh; 5. Bangladesh Council of Scientific and Industrial Research, Chittagong 4225, Bangladesh; 6. Department of Anthropology, Jahangirnagar University, Savar, Bangladesh; 7. Department of Animal Science and Nutrition, Faculty of Veterinary Medicine, Chittagong Veterinary and Animal Sciences University, Chittagong 4225, Bangladesh.

Corresponding author: Mohammad Mahmudul Hassan, e-mail: miladhasan@yahoo.com, AI: arif@ecohealthalliance.org, AKMS: saifuddincvu@yahoo.com,

AAF: faruqabdullahal103@gmail.com, SI: saif_mbio@yahoo.com,

SS: shahanajshano@gmail.com, MA: mahabub38@yahoo.com

Received: 25-09-2016, Accepted: 12-11-2016, Published online: 10-12-2016

doi: 10.14202/IJOH.2016.75-80 How to cite this article: Islam A, Saifuddin AKM, Faruq AA, Islam S, Shano S, Alam M, Hassan MM. Antimicrobial residues in tissues and eggs of laying hens at Chittagong, Bangladesh. Int J One Health 2016;2:75-80.

\begin{abstract}
Aim: Antimicrobial residue in animal food products is an important index of food safety. Antimicrobial residues could result from chemotherapeutic or chemoprophylactic use of drugs in food animals. This occurrence of residue in animal food products has received enormous worldwide attention from some local, international, and public health agencies. A crosssectional study was conducted from July to December 2009 to detect the antibiotic residues in tissues and eggs of laying hens at Chittagong of Bangladesh.
\end{abstract}

Materials and Methods: Microbial inhibition test (MIT) and thin layer chromatography (TLC) methods were used to detect antibacterial residues in poultry tissues (liver, kidney, breast, and thigh muscles) and eggs. The bacteria and $\mathrm{pH}$ of the MIT method were as follows: Bacillus subtilis on test agar medium with a $\mathrm{pH}$ of 7.2, Bacillus cereus with a $\mathrm{pH}$ of 6.0 , and Escherichia coli at $\mathrm{pH}$ with an 8.0.

Results: The overall prevalence of antibiotic residues detected by MIT was $64 \%$ in liver, $63 \%$ in kidney, $56 \%$ in breast muscle, $50 \%$ in thigh muscle, and $60 \%$ in eggs. There was significant variation in results between MIT and TLC ( $\mathrm{p}<0.05$ ). Tetracycline residues were found in $48 \%$ in liver, $24 \%$ in kidneys, $20 \%$ in thigh muscles, $26 \%$ in breast muscles, and $36 \%$ in eggs. Ciprofloxacin residues were found $46 \%$ in liver, $42 \%$ in kidneys, $34 \%$ in thigh muscles, $30 \%$ in breast muscles, and 30\% in eggs. Enrofloxacin residues were found $40 \%$ in livers, $36 \%$ in kidneys, $24 \%$ in thigh muscles, $20 \%$ in breast muscles, and 26\% in eggs. Amoxicillin residues were found $48 \%$ in livers, $30 \%$ in kidneys, $26 \%$ in thigh muscles, $22 \%$ in breast muscles, and $24 \%$ in eggs. The most frequently detected antibiotic residues by both MIT and TLC were found in liver tissue, tetracycline (48\%), ciprofloxacin (46\%), enrofloxacin (40\%), and amoxicillin (42\%) were found in liver. Breast muscle tissue was least likely to contain antibiotic residues $(24 \%)$. Tetracycline $(p=0.01)$ and amoxicillin $(p=0.03)$ residues had significant variation among the various poultry tissues and eggs.

Conclusions: A high percentage of tissues and eggs that could be available for human consumption had antibiotic residues. This study suggests that poultry meat and eggs should not be circulated to markets until the end of the drug's withdrawal period. It is also recommended to observe the withdrawal period of drugs before poultry slaughter or table egg distribution to avoid antimicrobial resistance and to inform both owners and consumers about the risks of antibiotic residues.

Keywords: antimicrobial, eggs, microbial inhibition test, poultry, thin layer chromatography, tissues.

\section{Introduction}

Antimicrobials and related other drugs are being widely used in poultry farms for different purposes such as treatment, prevention and control of diseases in Bangladesh and aid in combating stress in poultry farms resulting from environmental changes $[1,2]$.

Copyright: Islam, et al. This article is an open access article distributed under the terms of the Creative Commons Attribution 4.0 International License (http://creativecommons.org/licenses/ by/4.0/), which permits unrestricted use, distribution, and reproduction in any medium, provided you give appropriate credit to the original author(s) and the source, provide a link to the Creative Commons license, and indicate if changes were made. The Creative Commons Public Domain Dedication waiver (http:// creativecommons.org/ publicdomain/zero/1.0/) applies to the data made available in this article, unless otherwise stated.
Many of the antimicrobial used to treat bacterial infections in humans also have veterinary applications and they are used to treat infections in sick and injured animals and as prophylactics and growth promoters [3]. Poultry meat is popular and eggs are considered one of the ideal foods that are used extensively worldwide. Thus, egg industry is an important segment of the world food industry and an important part of human diet. Moreover, eggs provide a unique well-balanced nutrient for persons of all ages [4]. Their high nutrient content, low caloric value and ease of digestibility make eggs valuable in many therapeutic diets for adults [5]. The continuous use of the antibiotics can be a serious problem to consumers 
because of the possible existence of its residues in different food materials from animal sources such as milk and dairy products, poultry meat, and eggs $[6,7]$. Low-level doses of antibiotics consumed by humans for long periods can lead to allergies, and spreading of drug-resistant microorganisms, carcinogenic effect and potential harmful effect on human intestinal microflora [8]. The most common causes for the presence of antibiotic residues in food of animal origin are violation of withdrawal periods, overdosing of antibiotics and use of antibiotics banned for the treatment of economic animals [9]. Antimicrobial classes used to treat poultry are similar to those used in human medicine and include aminoglycosides, tetracycline, beta-lactams, quinolones, polypeptides, and sulphonamides. Microbial methods were the first choice of systematic detection of antibiotic residues in food in the past and are still mainstream screening methods. They allow determination of the presence of antibiotics in the sample and identification of specific antibiotic groups. Microbiological methods are better suited for the first step screening, but unfortunately, a single bacterial inhibition test for all antibacterial residues does not exist. Internationally recognized organizations such as the World Health Organization, Food and Agriculture Organization, Veterinary Medicine Directorate of the European Union, as well as the Food and Drug Administration in the USA, have set maximum tolerance levels or acceptable daily intakes for humans, and withholding times for pharmacologically active substances, including antimicrobial agents, before marketing [10]. Surveillance systems should be in place in conjunction with these regulations to ensure that these standards are met and that analyses can detect antimicrobials at less than the maximum residue levels.

In Bangladesh, poultry products are among the major sources of animal protein. Nowadays there is an increase in the number of poultry farms as they are considered an important economic source to increase individual income. The owners tend to rely on using antibiotics to avoid any economic losses. Routine screening tests for poultry products to detect antibiotic residues is not practiced, and there is no official standard method for detection of antibiotic residues in Bangladesh. Food animals slaughtered in the country are not screened for the presence of residues in any of the slaughterhouses in the country. No formal control mechanisms exist to protect the consumers against the consumption of meat and eggs containing harmful drug residues. The availability of simple and reliable screening systems for the detection of antibiotics is an essential tool in assuring the safety of food products.

In this study, a simple and fast method were surveyed for detection of antimicrobial residue in chicken meat tissues and eggs. Microbial inhibition test (MIT) and thin layer chromatography (TLC) are the sensitive and exact-reliable method for monitoring low amounts of different biological substances and qualitative detection of antimicrobial residues. TLC is analyzed by reverse phase liquid chromatography with fluorescence detection. Antibiotic residues might be potential hazards for human and animal health $[11,12]$. It also may be an obstacle to exporting poultry products to countries where such use is banned. This study investigated the prevalence of different antibiotic residues in various organ tissues (liver, kidney, breast muscle, and thigh muscle) and eggs of layer poultry at Chittagong district of Bangladesh.

\section{Materials and Methods}

\section{Ethical approval}

The study was approved by Animal Ethical Experimentation Committee of Chittagong Veterinary and Animal Sciences University (CVASU), Bangladesh.

\section{Study area, duration, and sample collection}

This study was conducted during the period of July to December 2009. Samples were collected from different layer farms of Sitakunda, Hathazari, Patiya, and Patenga of Chittagong district, Bangladesh. The five farms were selected randomly from a complete list of poultry farms of Chittagong District. A total of 50 laying birds and 50 eggs were purchased from five layer farms. From each hen, samples of liver, kidneys, breast and thigh muscle were collected for laboratory analysis.

\section{Sample analysis}

A microbial inhibition test (MIT) was conducted on each sample of organ tissue and egg to determine the presence or absence of antibiotic residues and the zone of inhibition was measured for each as described by Choi et al. [13]. The whole egg was homogenized, and samples were screened by a modified agar diffusion bioassay method as previously described. The test agar media Bacillus cereus at a pH of 6.0, Bacillus subtilis at a $\mathrm{pH}$ of 7.2, and Escherichia coli at a $\mathrm{pH}$ of 8.0 was included, and isolates were used from Bangladesh Council of Scientific and Industrial Research (BCSIR), Chittagong. Tissue samples of muscle, liver, kidney, and eggs were individually blended for 3-5 min depending on the tissue consistency. TLC was performed as previously described $[14,15]$ for detection of specific antibiotic residues.

\section{Statistical analysis}

The data were imported in Microsoft Excel 2010, cleaned and sorted. A statistical analysis was performed using STATA/IC-13 (College Station, Texas, USA). Descriptive analysis was performed using percentages for each outcome variable. AChi-square test and Fisher's exact test were used to determine differences between the proportion of samples that were positive and negative for antimicrobial residues across sample type by test type, media type, and antimicrobial type. Significant statistical difference was determined if $\mathrm{p}<0.05$.

\section{Results}

For the test agar using B. cereus with a $\mathrm{pH}$ of 6.0 , antibiotic residues were detected 68\% (34/50) in liver 
samples, 60\% (30/50) in kidney samples, 60\% (30/50) of breast muscle samples, $50 \%$ (25/50) of thigh muscle samples, and $64 \%(32 / 50)$ of egg samples. On the test agar with $B$. subtilis with a $\mathrm{pH}$ of 7.2 , antibiotic residues were detected at the following prevalence level in each sample type: 50\% (25/50) of liver, $66 \%$ (33/50) of kidney, $40 \%$ (20/50) of breast muscle, $44 \%$ $(22 / 50)$ of thigh muscle and 54\% (27/50) of egg. On the test agar with $E$. coli with a $\mathrm{pH}$ of 8.0, antibiotic residues were detected at the following prevalence level in each sample type: 74\% (37/50) of liver, 72\% $(36 / 50)$ of kidney, $70 \%(35 / 50)$ of breast muscle, $54 \%$ $(27 / 50)$ of thigh muscle and 60\% (30/50) of egg. A test was considered positive for antibiotic residues if an inhibition zone $>2 \mathrm{~mm}$ was detected (Table-1). There was no significant difference in the presence of antibody residue by sample type for each media-bacterial combination $(\mathrm{p}>0.05)$.

MITs consistently detected the presence of antibiotic residues more frequently than TLC. A significant difference was detected between the two test types for the following sample types: Kidney $66 \%$ $(33 / 50)$ and $34 \%(17 / 50)(\mathrm{p}=0.01)$, breast muscle $56 \%$ $(28 / 50)$ and $24 \%(12 / 50)(\mathrm{p}=0.01), 50 \%(25 / 50)$ and $26 \%(13 / 50)$ thigh muscle $(\mathrm{p}=0.02)$ and $60 \%(30 / 50)$ and $30 \%(15 / 50)$ eggs $(\mathrm{p}=0.01)$, respectively; no significant difference was noted for liver, 64\% (17/50) and $46 \%(23 / 50)$, respectively. Within one test type, there was no significant variation by sample type (Table-2).

To detect specific antibiotic residues, 250 samples of different poultry tissues and eggs were tested using TLC (Table-3). Among liver samples, 46\% (23/50) were positive for ciprofloxacin, $40 \%(20 / 50)$ for enrofloxacin, $48 \%(24 / 50)$ for tetracycline and $42 \%(21 / 50)$ for amoxicillin. Among kidney samples, $42 \%(21 / 50)$ were positive for ciprofloxacin, $36 \%$ $(18 / 50)$ for enrofloxacin, $24 \%$ (12/50) for tetracycline, and $30 \%(15 / 50)$ for amoxicillin. Both muscle types, breast and thigh tended to have a lower prevalence for specific residues $30 \%(15 / 50)$ and $34 \%(17 / 50)$ for ciprofloxacin, $20 \%(10 / 50)$ and $24 \%(12 / 50)$ for

Table-1: Percentage (number positive/number tested) of positive samples (inhibition zone $>2 \mathrm{~mm}$ ) on test agar media with various $\mathrm{pH}$ and bacterial species by sample type.

\begin{tabular}{|c|c|c|c|c|c|c|}
\hline Sample & $\begin{array}{c}\text { pH } 6.0 \text { and } \\
\text { B. cereus }\end{array}$ & $95 \%$ CI & $\begin{array}{c}\text { pH } 7.2 \text { and } \\
\text { B. subtilis }\end{array}$ & $95 \% \mathrm{CI}$ & $\begin{array}{c}\text { pH } 8.0 \text { and } \\
\text { E. coli }\end{array}$ & $95 \% \mathrm{CI}$ \\
\hline Liver & $68 \%(34 / 50)$ & $53.30,80.47$ & $50 \%(25 / 50)$ & $35.52,64.47$ & $74 \%(37 / 50)$ & $59.65,85.36$ \\
\hline Kidney & $60 \%(30 / 50)$ & $45.17,73.59$ & $66 \%(33 / 50)$ & $51.23,78.79$ & $72 \%(36 / 50)$ & $57.50,83.76$ \\
\hline $\begin{array}{l}\text { Breast } \\
\text { muscle }\end{array}$ & $60 \%(30 / 50)$ & $45.17,73.59$ & $40 \%(20 / 50)$ & $26.40,54.82$ & $70 \%(35 / 50)$ & $55.39,82.13$ \\
\hline $\begin{array}{l}\text { Thigh } \\
\text { muscle }\end{array}$ & $50 \%(25 / 50)$ & $35.52,64.47$ & $44 \%(22 / 50)$ & $29.99,58.74$ & $54 \%(27 / 50)$ & $39.32,68.18$ \\
\hline Egg & $64 \%(32 / 50)$ & $49.19,77.08$ & $54 \%(27 / 50)$ & $39.32,68.18$ & $60 \%(30 / 50)$ & $45.17,73.59$ \\
\hline
\end{tabular}

$\mathrm{CI}=$ Confidence interval

Table-2: Overall prevalence of the antimicrobial residues in different tissues and eggs of layer hens detected by MIT and TLC testing.

\begin{tabular}{lcccc}
\hline Sample & Prevalence in MIT (positive/n) & $\mathbf{9 5 \%}$ CI & Prevalence in TLC (positive/n) & 95\% CI \\
\hline Liver & $64(32 / 50)^{\mathrm{a}}$ & $49.19,77.08$ & $46(23 / 50)^{\mathrm{a}}$ & $31.81,60.67$ \\
Kidney & $66(33 / 50)^{\mathrm{a}}$ & $51.23,78.79$ & $34(17 / 50)^{\mathrm{b}}$ & $21.20,48.76$ \\
Breast muscle & $56(28 / 50)^{\mathrm{a}}$ & $41.25,70.00$ & $24(12 / 50)^{\mathrm{b}}$ & $13.06,38.16$ \\
Thigh muscle & $50(25 / 50)^{\mathrm{a}}$ & $35.52,64.47$ & $26(13 / 50)^{\mathrm{b}}$ & $14.63,40.34$ \\
Egg & $60(30 / 50)^{\mathrm{a}}$ & $45.17,73.59$ & $30(15 / 50)^{\mathrm{b}}$ & $17.86,44.60$ \\
Overall total & $59.2(29.6 / 50)$ & $45.17,73.59$ & $32(16 / 50)$ & $19.52,46.69$ \\
\hline
\end{tabular}

a,bSignificant difference detected between testing methods, not among organ type. MIT=Microbial inhibition test, $\mathrm{TLC}=$ Thin layer chromatography, $\mathrm{CI}=$ Confidence interval

Table-3: Prevalence of specific antibiotic residues found in areas tissues and eggs of layer hens detected by TLC.

\begin{tabular}{|c|c|c|c|c|c|c|c|c|}
\hline \multirow[t]{2}{*}{ Sample } & \multicolumn{2}{|c|}{ Ciprofloxacin } & \multicolumn{2}{|c|}{ Enrofloxacin } & \multicolumn{2}{|c|}{ Tetracycline } & \multicolumn{2}{|c|}{ Amoxicillin } \\
\hline & $\begin{array}{c}\text { Prevalence } \\
\text { (positive/n) }\end{array}$ & $95 \% \mathrm{CI}$ & $\begin{array}{l}\text { Prevalence } \\
\text { (positive/n) }\end{array}$ & $95 \% \mathrm{CI}$ & $\begin{array}{c}\text { Prevalence } \\
\text { (positive/n) }\end{array}$ & $95 \%$ CI & $\begin{array}{c}\text { Prevalence } \\
\text { (positive/n) }\end{array}$ & $95 \%$ CI \\
\hline vor & $46(23 / 50)^{a}$ & 31.81, & $40(20 / 50)^{a}$ & & $48(24 / 50)^{a}$ & & $48(24 / 50)^{a}$ & \\
\hline Kidney & $42(21 / 50)^{a}$ & $28.18,56.79$ & $36(18 / 50)^{a}$ & $22.91,50.80$ & $24(12 / 50)^{b}$ & & $30(15 / 50)^{b}$ & $17.86,44.60$ \\
\hline $\begin{array}{l}\text { Breast } \\
\text { muscle }\end{array}$ & $30(15 / 50)^{a}$ & $17.86,44.60$ & $20(10 / 50)^{a}$ & $10.03,33.71$ & $26(13 / 50)^{b}$ & $14.63,40.34$ & $22(11 / 50)^{\mathrm{b}}$ & $11.52,35.96$ \\
\hline Thigh & $34(17 / 50)^{a}$ & $21.20,48.76$ & $24(12 / 50)^{a}$ & $13.06,38.16$ & $20(10 / 50)^{\mathrm{b}}$ & $10.03,33.71$ & $26(13 / 50)^{\mathrm{b}}$ & $14.63,40.34$ \\
\hline Egg & $30(15 / 50)^{a}$ & $17.86,44.60$ & $26(13 / 50)^{a}$ & $14.63,40.34$ & $36(18 / 50)^{\mathrm{b}}$ & $22.91,50.80$ & $24(12 / 50)^{\mathrm{b}}$ & $13.06,38.16$ \\
\hline
\end{tabular}

a,bSignificant difference detected among organ type for a specific antibiotic. CI=Confidence interval, TLC=Thin layer chromatography 
enrofloxacin, 26\% (13/50) and 20\% (10/50) for tetracycline and $22 \%(11 / 20)$ and $26 \%(13 / 50)$ for amoxicillin, respectively. TLC of egg samples determined that $30 \%(15 / 50)$ were positive for ciprofloxacin, $26 \%(13 / 50)$ for enrofloxacin, 36\% (18/50) for tetracycline, and $24 \%(12 / 50)$ for amoxicillin. Although residues were more frequently detected in liver for all tests, the significance of this was not able to be determined based on the statistical tests that were conducted. However, there was a significant difference detected among sample type using TLC for tetracycline $(p=0.01)$ and amoxicillin $(p=0.03)$.

\section{Discussion}

MIT and TLC are used for preliminary screening of foods for antimicrobial residues because screening tests should be simple, cheap and fast [16]. Poultry meat and eggs are important foods for fulfilling the dietary needs of ever growing human population. The uncontrolled and unlimited use of these antibiotics may however lead to the accumulation of undesirable residues in the animal tissues and their products $[3,4]$. Notably, antibiotics are widely used in modern poultry industry in Bangladesh. They are used both for the prevention and treatment of diseases as well as feed additives to promote growth. Residues in eggs may be produced by administration of antibiotics to laying hens via food or drinking water used by veterinarians or farmers for therapy, prophylaxis and growth promotion in laying hens [7]. The application of plate microbial assays for the screening of antibacterial substances in food or feed is widely reported in literature [17]. The presence of tetracyclines showed the largest inhibition zone around the samples and the positive sample indicates that presence of tetracycline group of antibiotics. These results are consistent with the previous findings [18], and they detected the growth inhibition of $B$. cereus on an agar medium at $\mathrm{pH}-6.0$, and also identified residues of tetracycline. The current study findings differ with Okerman et al. [19], who reported $86 \%$ of the meat samples were positive on MIT the $\mathrm{pH} 6.0$ test agar media. Liver tissue had the most frequent positivity rate for MIT in comparison to the other simple types, but this was not significantly different. Our study demonstrates similarities with Przeniosło-Siwczyńsk and Kwiatek [20], who detected the beta-lactams antibiotic residues using $B$. subtilis strain Brilliant green agar on test agar media $\mathrm{pH}$ 7.2. Okerman et al. [19] found amoxicillin residues in poultry meat on test agar media $\mathrm{pH} 7.2$ using B. subtilis. The kidneys were most frequently positive on the MIT analysis when the test agar media had a $\mathrm{pH} 7.2$ compared to other media but statistically had no significant difference. Thus, in the presence of fluoroquinolones, the plate showed largest inhibition zone around the sample, which indicated quinolones residues. Okerman et al. [21] reported that MITs were suitable routine screening test for quinolones residues using $E$. coli as sensitive organism on test agar media $\mathrm{pH}$ 8.0. These study results have similarities with Choi et al. [13], who found more than $70 \%$ of the poultry meat samples showed positive on the test agar media $\mathrm{pH} 8.0$ using E. coli as indicator organism.

Chicken liver had the highest frequency of proportion of antibiotic residues for both MIT and TLC compared to the other simple types, though it was not significant. Similarly, Naeem and Rafiq [22] and Amjad et al. [23] found that chicken liver contained the highest level of enrofloxacin and ciprofloxacin residues when compared to the kidney and muscles. Andrej Kirbiš [9] reported tetracycline residues were most commonly detected in poultry liver. In the case of ciprofloxacin, it was observed that liver and kidney was the major harboring site showing the highest proportion of residues. A similar finding was reported by Naeem and Rafiq [22] and Amjad et al. [23]. Enrofloxacin residues were found in different percentages in liver, kidney, breast muscle, and thigh muscles and these findings have close similarities with Amjad et al. [23] who found that deposition of enrofloxacin as $44 \%$ for eggs and $57 \%$ for kidney. Amoxicillin residues were detected in various percentages in liver, kidney, breast muscle, thigh muscles, and eggs of laying hens and this finding agrees with Popelka et al. [14] and Thangadurai et al. [24] who detected amoxicillin residues in poultry meat using TLC. Tetracycline residues were found in livers, kidneys, thigh muscles, breast muscles and eggs in various percentages, and this finding has some similarities with Salehzadeh et al. [25], who detected that oxytetracycline residues above MRLs and the percentages were $28 \%, 95.55 \%$, and $18.88 \%$ in muscles, liver and kidney samples, respectively. In this study, we detected ciprofloxacin, enrofloxacin, tetracycline, and amoxicillin residues in table eggs. Lehotay et al. [26] developed an efficient multi-residue method for determination of fluoroquinolones antibiotics in eggs and found $60 \%$ residues which agree with the present research. Yang et al. [27] detected presence of tetracycline residues in poultry eggs and Luboslava et al. [28] identified amoxicillin residues in table eggs. Evidence suggests that more judicious use of antimicrobials in food animals will reduce the selection of resistant bacteria and help to preserve these valuable drugs for both human and veterinary medicine [29] adequate withdrawal period should be observed in all slaughter animals following the use of antibiotics. In addition, the use of antibiotics in food animals by nonveterinarian should be discouraged and may be illegal for certain antibiotics. This study demonstrates that high frequencies of antibiotic residues are detected in layer chickens and eggs.

\section{Conclusion}

We concluded that the test organisms $B$. cereus, B. subtilis, and E. coli can be used as routine screening methods for the presence antibiotic residues in poultry meat and eggs. The method described in this study is a simple, easy and less expensive and can be readily 
adapted by any laboratory for the detection antibiotic residues in products of food animals. The tissue and egg samples were demonstrated by MIT and TLC to be contaminated with high level of antibiotic residues. This indicates a clear disregard for withdrawal periods of the poultry products. The use and sometimes misuse of antimicrobials in food animal production has resulted in the emergence and dissemination of resistant pathogens and resistance genes. Further investigation is required for the quantitative determination of antibiotic residues in animal products.

\section{Authors' Contributions}

$\mathrm{AI}$ and $\mathrm{MMH}$ conducted the research and actively prepared the manuscript. AI, MMH, AKMS, and MA designed the work and provided the information. AI, AAF, MMH, MA, AKMS, SS, and SI participated in the manuscript preparation and advice during the research work. All the authors read and approved the final manuscript.

\section{Acknowledgments}

The authors are grateful to the CVASU, Bangladesh for providing financial (grant reference No. 2008/03) and technical support, respectively, to the project. The authors also acknowledge the BCSIR, Chittagong, Bangladesh for their laboratory support. This study was benefited from intellectual contributions from the PREDICT project of the United States Agency for International Development Emerging Pandemic Threats Program.

\section{Competing Interests} interests.

The authors declare that they have no competing

\section{References}

1. Pavlov AI, Lashev LI, Vachin RV. Residues of antimicrobial drugs in chicken meat and offals. Trakia J Sci 2008;6:23.

2. Ahaduzzaman M, Hassan MM, Alam M, Islam S, Uddin I. Antimicrobial resistance pattern against Staphylococcus aureus in environmental effluents. Res J Vet Pract 2014;2:13-6.

3. Sattar S, Hassan MM, Islam S, Alam M, Faruk M, Chowdhury $\mathrm{S}$, et al. Antibiotic residues in broiler and layer meat in Chittagong district of Bangladesh. Vet World 2014;7:738-43.

4. Mahmud T, Hassan MM, Alam M, Khan MM, Bari MS, Islam A. Prevalence and multidrug-resistant pattern of Salmonella from the eggs and egg-storing trays of retail markets of Bangladesh. Int J One Health 2016;2:7-11.

5. Ebubekir A, Ahmet S, Erog EK. Effect of egg shape index on mechanical properties of chicken eggs. J Food Eng 2008;85:606-12.

6. Chowdhury S, Hassan MM, Alam M, Sattar S, Bari MS, Saifuddin AK, et al. Antibiotic residues in milk and eggs of commercial and local farms at Chittagong, Bangladesh. Vet World 2015;8:467-71

7. Hassan MM, Amin KB, Ahaduzzaman M, Alam M, Al Faruk MS, Uddin I. Antimicrobial resistance pattern against $E$. coli and Salmonella in layer poultry. Res J Vet Pract 2014;2:30-5.

8. Nonga HE, Simon C, Karimuribo ED, Mdegela RH. Assessment of antimicrobial usage and residues in commercial chicken eggs from small holder poultry keepers in Morogoro municipality, Tanzania. Zoonoses Public Health 2010;57:339.

9. Kirbiš A. Microbiological screening method for detection of aminoglycosides, $\beta$-lactames, macrolides, tetracyclines and quinolones in meat samples. Slov Vet Res 2007;44:11-8.

10. Sirdar MM, Picard J, Bisschop S, Jambalang AR, Gummow B. A survey of antimicrobial residues in table eggs in Khartoum State, Sudan, 2007-2008. Onderstepoort J Vet Res 2012;79:E1-9.

11. Hassan M, Ahaduzzaman M, Alam M, Bari M, Amin K, Faruq AA. Antimicrobial resistance pattern against E. coli and Salmonella spp. in environmental effluents. Int J Nat Sci 2016;5:52-8.

12. Islam $\mathrm{A}$, Nath $\mathrm{AD}$, Islam $\mathrm{K}$, Islam $\mathrm{S}$, Chakma $\mathrm{S}$, Hossain MB, et al. Isolation, identification and antimicrobial resistance profile of Staphylococcus aureus in Cockroaches (Periplaneta americana). J Adv Vet Anim Res 2016;3:221-8.

13. Choi J, Yee AJ, Thompson D, Samoluk J, Mitchell M, Black WD. Determination of fluoroquinolone residues in animal tissues using Escherichia coli as indicator organism. J AOAC Int 1999;82:1407-12.

14. Popelka P, Nagy J, Germuska R, Marcincák S, Jevinová P, De Rijk A. Comparison of various assays used for detection of beta-lactam antibiotics in poultry meat. Food Addit Contam 2005;22:557-62.

15. Amjad H, Iqbal J, Naeem M. Analysis of some residual antibiotics in muscle, kidney and liver samples of broiler chicken by various methods. Proc Pak Acad Sci 2005;42:223-31.

16. Wachira WM, Shitandi A, Ngure R. Determination of the limit of detection of penicillin $G$ residues in poultry meat using a low cost microbiological method. Int Food Res J 2011;18:1203-8.

17. Van Egmond H. The 6 plate test: Screening on banned antibiotics in complete feedingstuffs, milk replacers and mineral feeds, competitive and sustainable growth programme-screening and identification methods for official control of banned antibiotics and growth promoters in feeding stuffs. Laboratory Instruction. Wageningen, The Netherlands: Institute of Food Safety; 2004.

18. Karraouan B, Bouchrif B, Ziyate N, Talmi A, Yahia KI, Cohen $\mathrm{N}$, et al. Evaluation of multi-plate microbial assay for the screening of antibacterial residues in poultry muscle. Eur J Sci Res 2009;35:311-7.

19. Okerman L, De Wasch K, Van Hoof J, Smedts W. Simultaneous determination of different antibiotic residues in bovine and in porcine kidneys by solid-phase fluorescence immunoassay. J AOAC Int 2003;86:236-40.

20. Przeniosło-Siwczyńska M, Kwiatek K. Evaluation of multiplate microbial assay for the screening of antibacterial substances in animal feeding stuffs. Bull Vet Inst Pulawy 2007;7:599-602.

21. Okerman L, Noppe H, Cornet V, de Zutter L. Microbiological detection of 10 quinolone antibiotic residues and its application to artificially contaminated poultry samples. Food Addit Contam 2007;24:252-7.

22. Naeem M, Rafiq KK. Determination of residues of quinolones in poultry products by pressure liquid chromatography. J Appl Sci 2006;6:373-9.

23. Amjad H, Iqbal J, Naeem M. Estimation of selected residual antibiotics in muscle, kidney, liver, and egg of layer chicken. Proc Pak Acad Sci 2006;43:29-37.

24. Thangadurai S, Shukla SK, Anjaneyulu Y. Separation and detection of certain beta-lactam and fluoroquinolone antibiotic drugs by thin layer chromatography. Anal Sci 2002;18:97-100.

25. Salehzadeh F, Madani R, Salehzadeh A, Rokhni N, Golchinefar F. Oxytetracycline residues in chicken tissues from Tehran slaughterhouses in Iran. J Nutr 2006;5:377-81. 26. Lehotay SJ, Lightfield AR, Geis-Asteggiante L, 
Schneider MJ, Dutko T, Ng C, et al. Development and validation of a streamlined method designed to detect residues of 62 veterinary drugs in bovine kidney using ultra-high performance liquid chromatography - Tandem mass spectrometry. Drug Test Anal 2012;4 Suppl 1:75-90.

27. Yang G, Dong A, Zeng Z, Huang X, Chen Z. Study of danofloxacin depletion in eggs of laying hens after oral administration. Int J Antimicrob Agents 2006;28:128-31.

28. Luboslava RR, Jozef N, Hanna R, Peter P, Pavlina J. Suitability of star and premi-test for the detection of amoxicillin residues in leying hens. Bull Vet Inst Pulawy 2006;50:367-71.

29. Donoghue DJ. Antibiotic residues in poultry tissues and eggs: Human health concerns? Poult Sci 2003;82:618-21. 